\title{
CULTURAL ASSIMILATOR AS A TECHNOLOGY FOR PREVENTING MALADAPTATION OF FOREIGN STUDENTS
}

\author{
Olga Panich $^{1^{*}}$, Nadejda Tkachenko ${ }^{1}$, Maya Khudaeva $^{1}$, Yelena Ovsyanikova ${ }^{2}$, Sergey \\ Sckilev $^{1}$, and Natalia Doronina ${ }^{1}$ \\ ${ }^{1}$ Department age and social psychology, Belgorod State National Research University, Russia.
}

\begin{abstract}
The article summarizes the author's experience of using the technology of cultural assimilator for the prevention of maladjustment of foreign students of the university. The procedure for the stage-by-stage construction of cultural assimilator episodes using the technique of a critical incident and an expert method is disclosed. The example shows the options for teaching Russian and Chinese students.
\end{abstract}

\section{Introduction}

Changes in the modern structure of the world over the past decades are accompanied by processes that have a significant impact on changing social reality. These processes have led to a significant increase in visitors and migrants to the territory of the Russian Federation. Migration on such a large scale creates many problems related not only to employment, acclimatization, but also to the intercultural adaptation of migrants to the new socio-cultural and educational environment.

Theoretical acquaintance with a foreign culture is not enough, and teaching should be conducted on the affective (establishing emotional relationships, the ability to give feedback) and behavioral (mastering the skills of non-conflict interaction), and not only on the intellectual level. One of the most recognized ways to get to know a new culture is the cultural assimilator method. This is a method of cognitive orientation of the subject in a new environment, which contributes to the growth of "cross-cultural sensitivity". According to N. M. Lebedeva, the use of this method is an effective means of transmitting information about differences between cultures, facilitating interpersonal contacts in a foreign cultural environment [7]. Its goal is not so much to assimilate-identify with members of a different ethnic group, but to develop an ethnically de-centered position aimed at increasing cross-cultural sensitivity $[1 ; 3 ; 4 ; 17 ; 20]$.

\footnotetext{
* Corresponding author: olga.pani4@yandex.ru
} 


\section{Materials and methods}

Based on the idea of basic dimensions of cultures, the Creator of the method, H. Triandis, designed a cultural assimilator that allows to increase the competence of a person on the problems of individualism and collectivism [18]. American researcher R. Brislin, attempted to create a universal cultural assimilator. He developed typical problem situations of cross-cultural interaction [2].

The structure of a particular episode of a cultural assimilator consists of three components: a situation of cross-cultural interaction, several interpretations, and feedback that allows you to get important information about someone else's culture. According to $\mathrm{H}$. Triandis, the use of such a programmed learning algorithm makes it possible to speed up and activate the process of getting acquainted with a new culture [18].

Initially, situations that reflect key differences between cultures are selected. An ideal situation is one that describes a typical interaction, contains a conflict, and carries important information about a foreign culture [7]. The source of such situations in our study were ethnic stereotypes of Chinese and Russian students recorded in communication with them, personal experience of cross-cultural interaction of authors-developers, as well as materials of interviews with experts. In our study, the experts were translators with long-term experience of working and living in a foreign cultural environment, as well as representatives of multicultural families.

Especially informative for collecting potential stories of future assimilator $\mathrm{s}$ is the "critical incident" method, which is widely used in organizational psychology and management [5]. This is an interview technique aimed at identifying non-standard events from the client's personal experience. In the context of ethnic psychology, the Respondent is asked to update the emotionally rich experience of cross-cultural interaction-to describe a situation that has significantly changed the attitude towards representatives of another culture, both in a negative and positive way. The potentially conflicting nature of such incidents is of particular research value, as it is based on the collision of mutual stereotypes, the inclusion of mechanisms of intergroup perception, and the use of protective behavioral strategies. The behavioral models of problem solving recreated in the cultural assimilator help to predict possible moments of interethnic disagreements.

At the second stage of creating a cultural assimilator , episodes are constructed based on expert analysis. Experts familiar with both cultures help determine the relevance and significance of the situation. With the help of experts, we have compiled a list of common Chinese names, the use of which made the situation more realistic. To formulate a specific episode, we used typical events of student life. As it turned out, it is important for the Chinese to use specific information about the main character - where exactly he came from, how long he has been studying a foreign language [6;13].

At the third stage, it is necessary to identify the reasons for the behavior of the characters in the situation. To create a Bank of explanations, we conducted a group discussion of ready-made episodes with foreign students. During the discussion, contact with the group is important, since the potentially conflicting nature of the situation describing cross-cultural interaction contributes to the closeness and lack of independence of the participants ' responses. Students who are at the initial stages of adaptation are guided by more competent fellow students, demonstrating intra-group conformism and passivity. Therefore, the organization of a group discussion has its own specifics. To increase activity and overcome conformal reactions, we emphasized the techniques of individual work that precede joint discussion - questionnaires or projective techniques. Written responses encourage the expression of true opinions and feelings that are not subject to group pressure. At the end of the work on creating a cultural assimilator, interpretations are selected based on the analysis of respondents 'and experts' responses. 


\section{Results}

Example of a cultural assimilator situation for participants of Russian-Chinese interaction:

A delegation of Chinese students came to the competition on programming in the city of Khabarovsk. The organizing Committee invited the Russian students learning the Chinese language, as interpreters and guides. The students took a tour of the city and went with the guests to have lunch at a restaurant. During the tour, Chinese students listened attentively to the story, asked questions and wrote down details, and they very politely communicated with the students. However, at dinner, the guests began to talk very loudly, throwing napkins and leftovers. Russian students were unpleasantly surprised. Why did the Chinese behave like this?

Explanations •

* their Parents brought them up badly.

* For the first time left without adult supervision, Chinese schoolchildren abused alcohol and therefore allowed themselves such behavior.

* The Chinese were very happy with the dinner, and so they were so relaxed.

* Chinese students are eating in a public place for the first time, so they don't know the rules of behavior.

Interpretation of the situation:

I. You have chosen option №1. This answer is not justified. The text of the situation does not give reason to believe that the Chinese students are poorly educated, on the contrary, during the tour they showed good manners in communication. Try to find another explanation.

II. You chose the explanation № 2. This explanation is not true. In Chinese society, the attitude of young people, especially schoolchildren, to alcohol is extremely distanced. In addition, the composition of Chinese delegations is subject to strict pre-selection, and groups of minors are accompanied by controlling adults.

III. You choose the explanation for № 3. This is the best answer. The free manner of behavior at the table, expressed by loud conversation, laughter shows a high degree of satisfaction of Chinese guests with the reception. Such looseness is a kind of tribute to the hospitality of the host country. The habit of throwing used napkins and leftover food on the floor is related to the style of behavior of Chinese staff. It is easier to organize a quick cleaning that does not attract the attention of customers from the floor than from the table.

IV. You chose the explanation No. 4. This is the wrong answer. Despite the relatively lower standard of living in China, restaurant visits are quite affordable for working Chinese, and family dinners in public catering places are traditional. Go back to the situation and choose a different explanation.

The situation of the cultural assimilator for Chinese students:

A student of the 10th grade of the Jiamus school Luo Yang, along with his classmates, came to the city of Khabarovsk, for programming competitions. The organizers warmly welcomed all participants and showed them the city. After the tour, the guests went to a restaurant for lunch. During lunch, Chinese students felt comfortable: they talked loudly, had fun, threw napkins on the floor. The Russians who were sitting at neighboring tables took their plates and went to another room. How can we explain the behavior of Russian visitors to the restaurant?

Explanations:

* They did not feel comfortable, as the restaurant was crowded with a large group of people.

* Russian customers wanted to move to a different, cheaper table.

* In Russia, it is not customary to talk loudly at a table in a public place, loud Chinese speech prevented Russian visitors from communicating with each other. 
* The restaurant Manager asked them to move to another table.

Interpretation of the situation:

I. You have chosen option №1. Russian visitors may have felt uncomfortable, as it is customary in Russian culture to take a more distant distance when communicating with strangers than in China. However, the situation does not indicate that there was not enough space in the hall. Find the best answer.

II. You chose option №2. This is not the correct answer. In Russian restaurants, the location of visitors does not affect the payment, if it does not provide additional services (for example, music or air conditioning). There is no such information in the situation. Try to find a more accurate answer.

III. You chose option № 3. This is the correct answer. Uninhibited behavior in a public place at a table, which is considered an indicator of a" good " dinner in China, is not always similarly regarded in Russia. So napkins and leftovers of food Russian usually put on the empty plates.

IV. You chose option № 4. This explanation is possible, but there is nothing in the description of the situation that indicates the intervention of the restaurant administration. Look for a more appropriate explanation.

\section{Discussion}

The complete set of the cultural assimilator is focused on the way it is used. So for individual work, the episode is divided into structural elements and has a text on 5-6 pages. In group work, the Assimilator is used as a scenario, as an illustration of the problem for subsequent discussion, and even as a means of measuring competence in cross-cultural interaction.

We offered Chinese students a situation that ended with questions about the reasons for the behavior of representatives of Russian culture. We used a form of group work with a cultural assimilator, when after getting acquainted with the situation, explanations are presented on the Board, and each participant chooses their own version. Then there is a turn-by-turn introduction to the feedback theses, followed by a discussion.

Reflection on the use of the cultural assimilator in working with foreign students allows us to state the high emotional involvement of participants in expressing explanations of the characters ' behavior and a clear interest in interpretation options in the feedback. During the discussion, the identification mechanism is activated - when students put themselves in the place of the main character.

Observations also show that working with a cultural assimilator is especially effective at the stage of first acquaintance with the culture - during the adaptation period, and with those students who are motivated to migrate for a long time.

As our experience of working with a cultural assimilator in the mode of sociopsychological training has shown, ready-made situations can perform both developmental and diagnostic functions. Each specific episode of a cultural assimilator is a variant of a projective situation that reflects the contradictions of real interethnic interaction or the inadequacy of interethnic mutual perception. Therefore, the behavioral responses and statements of participants in the analysis of these situations served as a source of information about the level of stereotypical perception. The cultural assimilator is used for understanding one's own ethnocentricity and interpreting behavior based on the characteristics of another culture; modeling positive intergroup behavior, forming attitudes to tolerant behavior in a foreign cultural environment; reducing anxiety in situations of cross-cultural interaction. 


\section{Conclusion}

Thus, the cultural assimilator is a method of cognitive orientation of the subject in a new cultural environment, contributing to the growth of intercultural sensitivity. The procedure for constructing a cultural assimilator involves identifying potentially conflicting situations that reflect key differences between cultures. And analysis of isomorphic attributions ethnospecific reasons for the behavior of characters in the situation. The use of the cultural assimilator is multivariate in form (individual, group, frontal), method of use (didactic and empirical), and functions performed (developmental and diagnostic). The cultural assimilator can be used as a method of prevention of maladaptation of foreign university students. The work carried out by the authors showed that the construction of a cultural assimilator can be optimized using the critical incident technique and the expert method. Thus, the theoretical concepts of the use of cultural assimilator technology in educational practice are expanded.

\section{References}

1. Albert, R.D. The intercultural sensitizer or culture assimilator : A cognitive approach // Handbook of intercultural training / Ed. by D.Landis, R.W.Brislin. New York etc.: Pergamon Press, 1983. Vol. 2. P. 186-217.

2. Brislin, R.W., Cushner, K., Cherrie, C, Yong, M. Intercultural interactions: A practical guide. Beverly Hills (Cal) etc.: Sage, 1986.

3. Castro, A., Aristegui, I. Cultural Competences of International Students: Its Role on Successful Sociocultural and Psychological Adaptation. Positive Psychology in Latin America. Cross-Cultural Advancements in Positive Psychology. Vol 10, year 2014, p. 89-110.

4. Kiyashchuk, T.V., Kiyashchuk, A. A., Sardarian A.R. Special Aspects of International Students' Socio-Psychological Adaptation at Modern Universities // Espacios. Vol. 39 (№ 23).2018 P. 11-20

5. Kolosova, A.A. «Critical incident» as a method of cross-cultural training // Collection of materials of the third all-Russian scientific and practical conference " Practical ethnopsychology: current problems and prospects of development»: 11-12 marta 2011 g. - M.: MGPPU, $2011-130$.

6. Cross-cultural methods of diagnostics of social and psychological adaptation of Russian and Chinese students: educational and methodological guide / V.V. Kalita, N.V. Vinichuk, O.E. Panich, M.A. Melnikova, M.V. Dolgova, I.L. Aristova ; [pod obshch. red. V.V. Kality]. - Vladivostok : Dal'nevost. federal. un-t, 2013.

7. Lebedeva, N. M., Stefanenko, T. G., Luneva, O. V. The training of ethnic tolerance for schoolchildren. Textbook for students of psychological specialties.-M.: MAKS Press, 2012.

8. Lynn, S., Douglas, F. Instructional Adaptation for Students at Risk. The Journal of Educational Research Published. Vol 86, year 2010, p. 70-84.

9. Machart, R. Asian Students Abroad: Missing the Boat of Adaptation?. In: Song X., Sun Y. (eds) Transcultural Encounters in Knowledge Production and Consumption. Encounters between East and West (Intercultural Perspectives). Springer, Singapore. 2018, p. 125-139.

10. Macumoto, D. Psychology and culture. SPb.: Piter, 2003.-720 s. 
11. Meng, Q., Zhu, C., Cao, C. Chinese international students' social connectedness, social and academic adaptation: the mediating role of global competence. Higher Education. Springer Netherlands. 2017, p. 1-17.

12. Nigmatullinaa, I. A., Gerasimenko, J. A. Correction of School Disadaptation of Teenagers by Art Therapy Methods // International journal of environmental and science education. 2016 V. 11, №. 8, p. 2037-2045

13. Panich, O.E. Psychology of interethnic interaction: educational and methodological guide. - Belgorod: ID «Belgorod», 2013.

14. Sandel, T.L.. “Oh, I'm Here!”: Social Media's Impact on the Cross-cultural Adaptation of Students Studying Abroad. Journal of Intercultural Communication Research. Vol 43, year 2014. Number 01, p. 1-29.

15. Schartner, A., Young, T.J. Towards an integrated conceptual model of international student adjustment and adaptation. European Journal of Higher Education. Vol 6, year 2016, number 4, p. 372-386.

16. Schotte, K., Stanat, P., Edele, A. Is Integration Always most Adaptive? The Role of Cultural Identity in Academic Achievement and in Psychological Adaptation of Immigrant Students in Germany. Journal of Youth and Adolescence.year 2017, p. 122.

17. Serebryakova, R.V. Cultural assimilator as an effective method of preparing for cross-cultural interaction, contributing to the preservation and development of the culture of the indigenous peoples of the North. - Juvenis scientia. - 2018. - № 10. - S. 61-64.

18. Triandis, H. Culture and Social Behavior. New York: McGraw-Hill, 1994.

19. Xiulan, Y. From Passive Assimilation to Active Integration: The Adaptation of Rural College Students to Cities. Chinese Education \& Society Published. Vol 48, year 2015, number 2, p. 92-104.

20. Zhang, Y., Wang, Y. A Qualitative Study of the Adaptation of Rural College Students on College Life. Chinese Education \& Society Published. Vol 48, year 2015, number 2, p. 105113. 